\title{
Identification of novel substrates for human checkpoint kinase Chk1 and Chk2 through genome-wide screening using a consensus Chk phosphorylation motif
}

\author{
Myoung-Ae Kim ${ }^{1,2}$, Hyun-Ju Kim ${ }^{1,2}$, \\ Alexandra L. Brown ${ }^{3}$, Min-Young Lee ${ }^{1,2}$, \\ Yoe-Sik Bae ${ }^{1,2}$, Joo-In Park, \\ Jong-Young Kwak ${ }^{1,2}$, Jay H. Chung ${ }^{3}$ \\ and Jeanho Yun ${ }^{1,2,4}$ \\ ${ }^{1}$ Medical Research Center for Cancer Molecular Therapy \\ ${ }^{2}$ Department of Biochemistry \\ College of Medicine, Dong-A University \\ Busan 602-714, Korea \\ ${ }^{3}$ Laboratory of Biochemical Genetics \\ NHLBI, NIH, 10 Center Drive \\ Bethesda, Maryland 20892, USA \\ ${ }^{4}$ Corresponding author: Tel, 82-51-240-2919; \\ Fax,82-51-241-6940; E-mail, yunj@dau.ac.kr
}

Accepted 15 February 2007

Abbreviations: Chk, checkpoint kinase; FANCG, fanconi anemia complementation group G; GATA3, GATA binding protein 3; GST, glutathione S-transferase; HDAC, histone deacetylase; HEK, human embryonic kidney; IP, immunoprecipitation; IPTG, isopropyl-1-thio$\beta$-D-galactopyranoside; IR, $\gamma$-irradiation; MAD1a, mitotic arrest deficient protein 1a; PGC-1 $\alpha$, peroxisome proliferators-activated receptor $\gamma$ coactivator-1 $\alpha$; PP2A, protein phosphatase $2 A$; PP2A PR130, protein phosphatase 2 regulatory subunit B; Rad51D, RADidation sensitivity abnormal/year RAD-related 51D; ST5, suppression of tumorigenicity 5

\begin{abstract}
Checkpoint kinase 1 (Chk1) and Chk2 are effector kinases in the cellular DNA damage response and impairment of their function is closely related to tumorigenesis. Previous studies revealed several substrate proteins of Chk1 and Chk2, but identification of additional targets is still important in order to understand their tumor suppressor functions. In this study, we screened novel substrates for Chk1 and Chk2 using substrate target motifs determined previously by an oriented peptide library approach. The potential candidates were selected by genomewide peptide database searches and were examined by in vitro kinase assays. ST5, HDAC5, PGC-1 $\alpha$, PP2A PR130, FANCG, GATA3, cyclin G, Rad51D and MAD1a
\end{abstract}

were newly identified as in vitro substrates for Chk1 and/or Chk2. Among these, HDAC5 and PGC-1 $\alpha$ were further analyzed to substantiate the screening results. Immunoprecipitation kinase assay of fulllength proteins and site-directed mutagenesis analysis of the target motifs demonstrated that HDAC5 and PGC-1 $\alpha$ were specific targets for Chk1 and/or Chk2 at least in vitro.

Keywords: checkpoint kinase 1; checkpointkinase 2; DNA damage; phosphorylation; substrate specificity

\section{Introduction}

The eukaryotic DNA damage checkpoint ensures the maintenance of genomic integrity and suppression of tumorigenesis in the presence of DNA damage or incomplete DNA replication by the regulation of various cellular responses, including cell cycle progression and DNA repair (Zhou and Elledge, 2000). It has been demonstrated that the most of the components of the DNA damage checkpoint are either tumor suppressors or are closely related to cancer. For example, proximal kinases such as ATM and ATR, mediator molecules such as Brca1 and PML, and effector kinases such as Chk1 and Chk2 have been found to play roles as tumor suppressors. Upon DNA damage, checkpoint kinases Chk1 and Chk2 are activated by the upstream proximal kinases, ATM and ATR and determine cellular responses by regulating target protein functions through phosphorylation (Bartek and Lukas, 2003). To date, many important regulatory proteins have been revealed as substrates for Chk1 and Chk2 including Cdc25A, Cdc25C (Ahn and Prives, 2002), p53 (Shieh et al., 2000), Brca1 (Lee et al., 2000), PML (Yang et al., 2002), E2F (Stevens et al., 2003) and $p 73 \alpha$ (Gonzalez et al., 2003). These studies indicate that both Chk1 and Chk2 play a central role in the cellular response to DNA damage by regulating multiple cellular processes including the cell cycle checkpoint, the transcription machinery, apoptosis and senescence as well as DNA repair.

Chk2 mutations were observed in Li-Fraumeni syndrome and in many sporadic cancers (Bell et al., 1999; Bartek and Lukas, 2003). Chk1 mutations were found in cervical and rectal cancers (Bertoni et 
al., 1999; Bartek and Lukas, 2003). Studies utilizing a Chk2-deficient mouse model showed that Chk2 deficiency resulted in the loss of checkpoint function, resistance to $\gamma$-irradiation (IR), defective to p53 function and apoptosis (Hirao et al., 2000; Takai et al., 2002). On the other hand, Chk1 deficiency in mouse or in embryonic stem (ES) cells is lethal indicating that Chk1 function is essential for normal development and cell growth (Takai et al., 2000). These studies indicated that Chk1 and Chk2 functions are closely related to tumorigenesis. Furthermore, the wide range of abnormal phenotypes of Chk1- and Chk2-deficient cell lines and mouse models suggest that Chk1 and Chk2 play an important role in many cellular processes through phosphorylation of a large number of target proteins. Therefore, the identification of physiological substrates is an essential step to understanding their tumor suppressor functions and to understanding the underlying regulatory mechanisms of the DNA damage response.

To identify novel substrates for Chk1 and Chk2, we employed a genome-wide peptide database search using a consensus Chk1/Chk2 substrate phosphorylation motif established previously from the oriented peptide library analyses (O'Neill et al., 2002). This approach allows us to find novel candidate substrates that previously could not be identified in the conventional biochemical study. By examining direct phosphorylation of those candidates by in vitro kinase assay, we could identify novel targets for Chk1 and Chk2. Among positively phosphorylated candidates, we further analyzed HDAC5 and PGC- $1 \alpha$ for Chk1/Chk2-dependent phosphorylation and demonstrated that HDAC5 and PGC- $1 \alpha$ are specific substrates for Chk1 and/or Chk2. Newly identified targets should contribute to the understanding of the tumor suppressor functions of Chk1 and Chk2 and of the regulatory circuit of the DNA damage response.

\section{Materials and Methods}

\section{Plasmids and GST fusion protein production}

For Glutathione S-transferase (GST)-fusion peptide expression plasmids of 43 candidates, complementary oligonucleotides encoding 13 amino acids of the Chk1/Chk2 phosphorylatoin target site listed in Table 1 were synthesized and subcloned into the EcoRI/ Xhol site of pGEX-5X vector (Amersham Pharmacia Biotech, Piscataway, NJ). The sequence of the oligonucleotides is available upon request. Flag-HDAC5 was kindly provided by Eric Verdin and Flag-PGC-1 $\alpha$ was generated by subcloning PGC- $1 \alpha$ CDNA (a gift from Bruce Spiegelman) into the $\mathrm{pCMV-Tag2B}$ vector (Stratagene, La Jolla, CA). The pGEX-HDAC5 fragment (amino acids 386-600) and pGEX-PGC-1 $\alpha$
Table 1. Summary of Chk1 and Chk2 in vitro kinase assay results of selected candidates.

\begin{tabular}{|c|c|c|c|}
\hline \multirow[t]{2}{*}{$\begin{array}{c}\text { Protein } \\
\text { name }\end{array}$} & \multirow[t]{2}{*}{ Target sequence } & \multicolumn{2}{|c|}{$\begin{array}{c}\text { Relative } \\
\text { phosphory- } \\
\text { lation }^{\mathrm{a}}\end{array}$} \\
\hline & & chk1 & chk2 \\
\hline $101 \mathrm{~F} 6$ & 34-VAVLARPGSSLFS-46 & - & - \\
\hline Aladin & 114-ALALCRWASSLHG-126 & - & ++ \\
\hline AMPK $\alpha 2$ & 492-AAGLHRPRSSFDS-504 & - & + \\
\hline APC4 & 443-EVLLHRLASFHRV-55 & ++ & ++ \\
\hline Beclin1 & 287-NFRLGRLPSVPVE-299 & + & + \\
\hline Caspase6 & 71-RDNLTRRFSDLGF-83 & ++ & + \\
\hline Caspase9 & 186-CEKLRRRFSSLHF-198 & ++ & + \\
\hline CLIF & 490-ILDLQRLQSSSYL-502 & + & ++ \\
\hline Cyclin F & 187-LHCLGRVLSLFED-199 & - & - \\
\hline Cyclin G & 168-NLPLERRNSINFE-180 & ++ & +++ \\
\hline DNMT3 & 886-QRLLGRSWSVPVI-898 & - & - \\
\hline EDD & 285-RSSLSRLGSSRVL-297 & ++ & + \\
\hline FANCA & 1079-KRILLRLPSSVLC-1091 & ++ & - \\
\hline FANCE & 366-SLFLGRILSLTSS-378 & + & - \\
\hline FANCG & 418-EELLSRTSSLLPK-430 & +++ & +++ \\
\hline GATA-3 & 394-PAALSRHMSSLSH-406 & ++ & +++ \\
\hline GLI1 & 536-PVSLERRSSSSSS-548 & ++ & + \\
\hline HDAC4 & 624-HRPLSRAQSSPAS-636 & + & - \\
\hline HDAC5 (\#1) & 490-HRPLSRTQSSPLP-502 & + & +++ \\
\hline HDAC5 (\#2) & 653-HQALGRTQSSPAA-665 & + & - \\
\hline $\mathrm{HDAC7}$ & 438-HRPLSRAQSSPAA-450 & ++ & + \\
\hline Hsp27 & 74-SRALSRQLSSGVS-86 & ++ & ++ \\
\hline hTERT & 448-LVQLLRQHSSPWQ-460 & - & - \\
\hline MAD1a & 691-EVHLRRQDSIPAF-703 & ++ & +++ \\
\hline Mirk & 546-PRYLGRPPSPTSP-558 & - & - \\
\hline MKP-7 & 500-LSPLHRSGSVEDN-512 & + & - \\
\hline MOP9 & 460-ILDLQRLQSSSYL-472 & ++ & - \\
\hline NFIB & 256-GVNLQRSLSSPPS-268 & ++ & ++ \\
\hline p63 & 613-PSHLLRTPSSAST-625 & ++ & + \\
\hline PCTAIRE & 274-DFGLARAKSVPTK-286 & + & ++ \\
\hline PGC-1 & 277-NKTIERTLSVELS-289 & +++ & +++ \\
\hline PP2A PR130 & 173-SFGLLRSSSVEEK-185 & ++ & + \\
\hline PRIC-285 & 500-TCALPRPWSVPPL-512 & - & - \\
\hline Rad51B & 232-NKFLAREASSLKY-244 & ++ & ++ \\
\hline Rad51D & 261-KPALGRSWSFVPS-273 & ++ & +++ \\
\hline RORB & 115-AEALARVYSSSIS-127 & ++ & - \\
\hline SENP1 & 216-PLHLSRCLSSSKN-218 & ++ & - \\
\hline Separin & 670-VCHLGRLGSVSEA-682 & + & - \\
\hline SMC5 & 17-KRALPRDPSSEVP-29 & - & + \\
\hline Socs3 & 175-PLVLSRPLSSNVA-187 & - & - \\
\hline SREBP & 737-SYFLSRAQSLCGP-749 & + & - \\
\hline ST5 & 22-RGTLSRSQSVSPP-34 & ++ & ++ \\
\hline XRCC3 & 46-VWHLLRTASLHLR-58 & - & - \\
\hline
\end{tabular}

Amino acid sequences and relative level of phosphorylation by Chk1 and Chk2 of target motifs of tested candidates are shown. ${ }^{\text {a Relative level of }}$ phosphorylation; -, Not phosphorylated; +, weakly phosphorylated; ++, mildly phosphorylated; +++, strongly phosphorylated. 
fragment (amino acids 201-400) were generated by PCR with primers: HDAC5 F 5'-ATCCCGGAATTCGAGAGGCAGGCCCTCCAG-3', HDAC5 R 5'-CGGCCGCTCGAGATCCTCCTCCTCCTCCCC-3', PGC-1 $\alpha$ F 5'-ATCCCGGAATTCAAGCCACAAAGACGTCCC-3', PGC-1 $\alpha$ R 5'-CGGCCGCTCGAGTATATTAATGAGTATTTC-3'. The amplified fragments were digested with EcoRI-Xhol and subcloned into pGEX$5 X$ vector. The mutations of HDAC5 S498A and of Flag-PGC-1 $\alpha$ S285A were generated by using the QuickChange site-directed mutagenesis kit (Stratagene) and the following primers: 5'-CCCCTGAGCCGCACTCAGGCCTCACCGCTGCCGCAGAGTCCC-3' for S498A of HDAC5, 5'-ACTATTGAACGCACCTTAGCTGTGGAGCTCTCTGGAACTGCA-3' for $\mathrm{S} 285 \mathrm{~A}$ of PGC-1 $\alpha$. All mutations were verified by sequencing.

GST-fusion proteins were expressed in Escherichia coli BL21 (DE3) by induction with isopropyl1-thio- $\beta$-D-galactopyranoside (IPTG) and purified from cleared cellular lysate by affinity chromatography using gluthathione-sepharose beads (Amersham Pharmacia) as described previously (Ahn et al., 2006).

\section{In vitro kinase assays}

In vitro kinase assays for Chk1 and Chk2 were performed as described previously (Brown et al., 1999). Briefly, $0.1 \mu \mathrm{g}$ of recombinant GST-Chk2 (Brown et al., 1999) or GST-Chk1 (Upstate biotechnology, Lake Placid, NY) and $2 \mu \mathrm{g}$ of purified GST-fusion protein substrates were incubated in a reaction buffer containing $10 \mathrm{mM}$ Hepes ( $\mathrm{pH} 7.5), 50 \mathrm{mM} \mathrm{KCl}, 10$ $\mathrm{mM} \mathrm{MgCl}_{2}, 0.5 \mathrm{mM}$ EDTA, $1 \mathrm{mM}$ DTT, $50 \mu \mathrm{M}$ ATP and $5 \mu \mathrm{Ci}$ of $\left[\gamma^{32}{ }^{32} \mathrm{P}\right.$ ATP. The mixture was incubated at $30^{\circ} \mathrm{C}$ for $30 \mathrm{~min}$ and electrophoresed in a denaturing polyacrylamide gel. The gel was stained by coomassie blue to visualize substrates, dried and the phosphorylated proteins were detected by autoradiography.

\section{Cell culture and transfection}

HEK293 cells were cultured in DMEM supplemented with $10 \%$ FBS (Gibco, Rockville, MD). DNA transfections were performed using Lipofectin reagent (Invitrogen, Carlsbad, CA) according to the manufacturer's instructions.

\section{Immunoprecipitation, western blotting and IP-kinase assay}

For HDAC5 and PGC-1 $\alpha$ immunoprecipitation (IP)kinase assays, $8 \mu \mathrm{g}$ of Flag-tagged expression plasmids were transfected into HEK293 cells and harvested $48 \mathrm{~h}$ later with lysis buffer $(50 \mathrm{mM}$ Tris $[\mathrm{pH}$ 7.5], $50 \mathrm{mM} \mathrm{NaCl}, 0.5 \%$ Triton X-100, 1 mM EDTA,
$1 \mathrm{mM}$ DTT containing phosphatase and protease inhibitors). Cleared lysates were immunoprecipitated with anti-Flag antibody (M2; Sigma, St Louis, MO) and in vitro kinase assays were performed as described above using the proteins bound to immunoprecipitated beads as substrates. The immunoprecipitated protein level was determined by Western blotting with anti-Flag antibody and the ECL detection system (Amersham Pharmacia) as described previously (Chae et al., 2005).

\section{Results}

\section{Identification of novel substrates for Chk1 and Chk2 using the consensus phosphorylation motif}

Since Chk1 and Chk2 are prime effectors in the DNA damage checkpoint, we decided to identify novel target proteins to understand the regulatory circuit of the DNA damage response signal pathway. To find potential target candidates, we screened the human peptide sequence library utilizing the Chk1 and Chk2 consensus phosphorylation site motif derived previously from the oriented peptide library approach (O'Neill et al., 2002) and the genome-wide search programs the SCANSITE (Yaffe et al., 2001) and PIR pattern search (http://pir.georgetown.edu/pirwww/ search/pattern.shtml). More than 5,000 peptides were found harboring the Chk1/2 consensus phosphorylation motif. The previously identified endogenous substrates such as Cdc25A, B, C, Brca1 and E2F1 were also found. Among the screened peptides, we finally selected 43 putative candidates by considering several factors such as nuclear localization, target site conservation between species and known functions.

In order to test potential candidates, glutathioneS-transferase (GST)-fusion proteins containing 13 amino acids spanning the target motifs of candidates were generated and used as substrates in Chk1 and Chk2 in vitro kinase assays. GST-fusion proteins containing Cdc25C Ser216 and Brca1 Ser988 motifs were used as positive controls. The in vitro kinase assays were performed at least in duplicate and gave essentially the same results. Representative results for all 43 candidates are shown in Figure 1. Consistent with a previous report (O'Neill et al., 2002), the Brca1 Ser988 motif was mainly phosphorylated by Chk2 while the Cdc25C Ser216 motif was more strongly phosphorylated by Chk1. Using these two positive controls as a strong and weak phosphorylation standards respectively, we determined the relative level of phosphorylation of the candidates as summarized in Table 1.

Among 43 candidates examined, 8 peptides were not phosphorylated by either Chk1 or Chk2. Several 

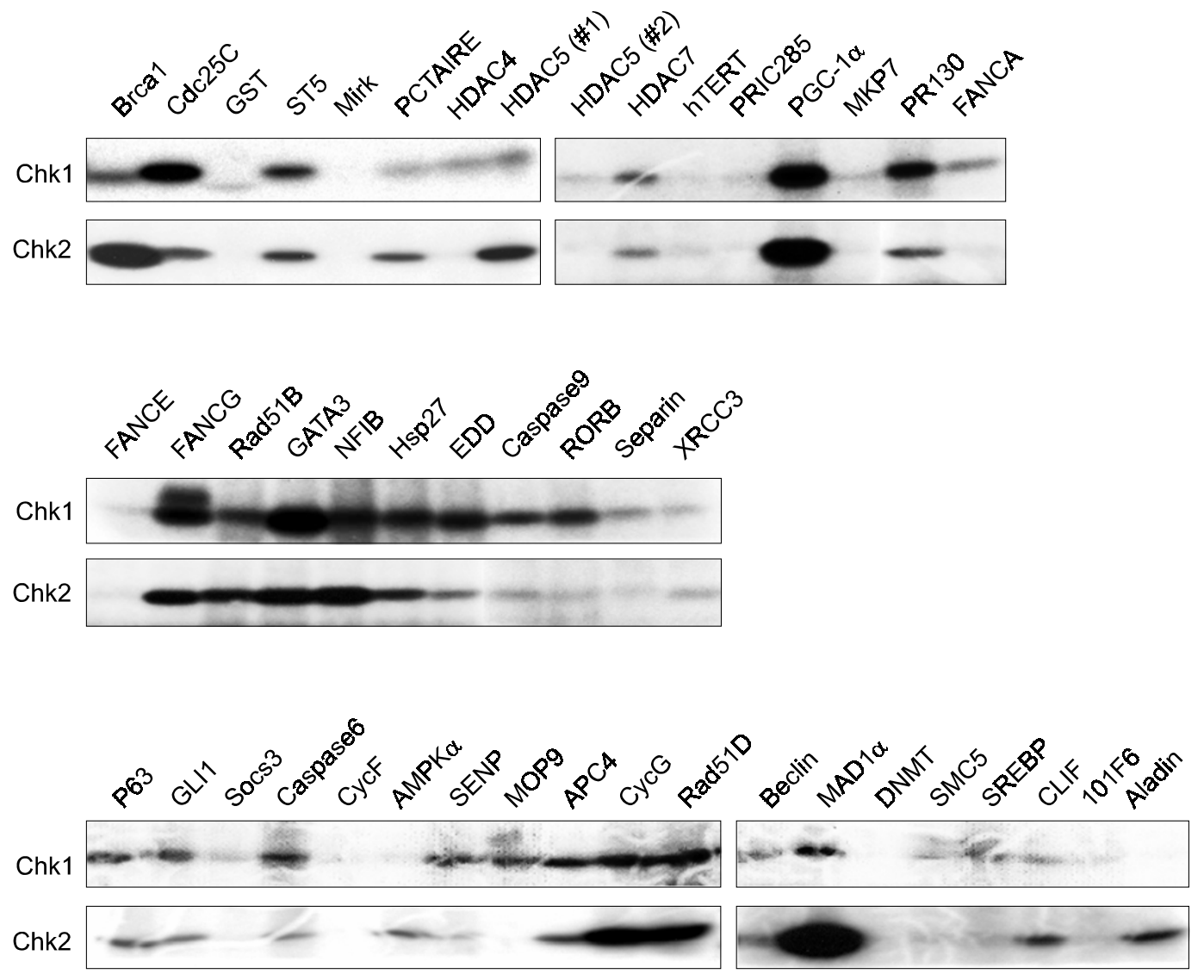

Figure 1. Representative result for the phosphorylation of candidate substrates by Chk1 and Chk2. GST-fusion proteins containing 13 amino acids spanning the target motifs of candidates were used as substrates in Chk1 and Chk2 in vitro kinase assays as described in Materials and Methods. Brca1 Ser988 and Cdc25C Ser216 motifs were used as positive controls and the relative phosphorylation level of candidates was determined by comparison to the positive controls as shown in Table 1.

candidates were phosphorylated strongly including ST5, HDAC5 (\#1), PGC-1 $\alpha$, PP2A PR130, FANCG, GATA3, cyclin G, Rad51D and MAD1a. While ST5, PGC-1 $\alpha$, FANCG, GATA-3 and Rad51D were phosphorylated similarly by both Chk1 and Chk2, PP2A PR130 was phosphorylated more strongly by Chk1 and HDAC5 (\#1) and MAD1a were phosphorylated more strongly by Chk2. These results suggest that members of a sub-group of the identified proteins act as substrates for both Chk1 and Chk2, whereas members of a different sub-group of the proteins are phosphorylated specifically by either Chk1 or Chk2.

\section{Larger fragments of HDAC5 (\#1) and PGC-1 $\alpha$ are phosphorylated by Chk1 and/or Chk2}

To further substantiate our screening results, we decided to select two substrates and to test their phosphorylation by Chk1 and Chk2 in more physiological settings. In order to identify novel regula- tory pathways, we choose HDAC5 and PGC- $1 \alpha$ because their known function in previous studies is relatively less linked to the DNA damage response or to tumorigenesis compared to the other identified substrates (See Discussion). First, to avoid possible artifacts due to using short target motifs as kinase substrates, we examined the phosphorylation of larger fragments of HDAC5 (\#1) and PGC-1 $\alpha$ by Chk1 and Chk2. Approximately 200 amino acid fragments of HDAC5 (398-600) and PGC-1 $\alpha$ (201400) were generated as GST-fusion proteins and were used as substrates for the in vitro kinase assay. As shown in Figure 2, the HDAC5 fragment containing \#1 target motif was phosphorylated by both Chk1 and Chk2. Previously, the GST-fusion protein of the 13 amino acid motif of HDAC5 (\#1) was not strongly phosphorylated by Chk1 (Figure 1). The strong phosphorylation of the 200 amino acids fragment of HDAC5 (\#1) by Chk1 may be due to several possible reasons. Firstly, the larger fragment 


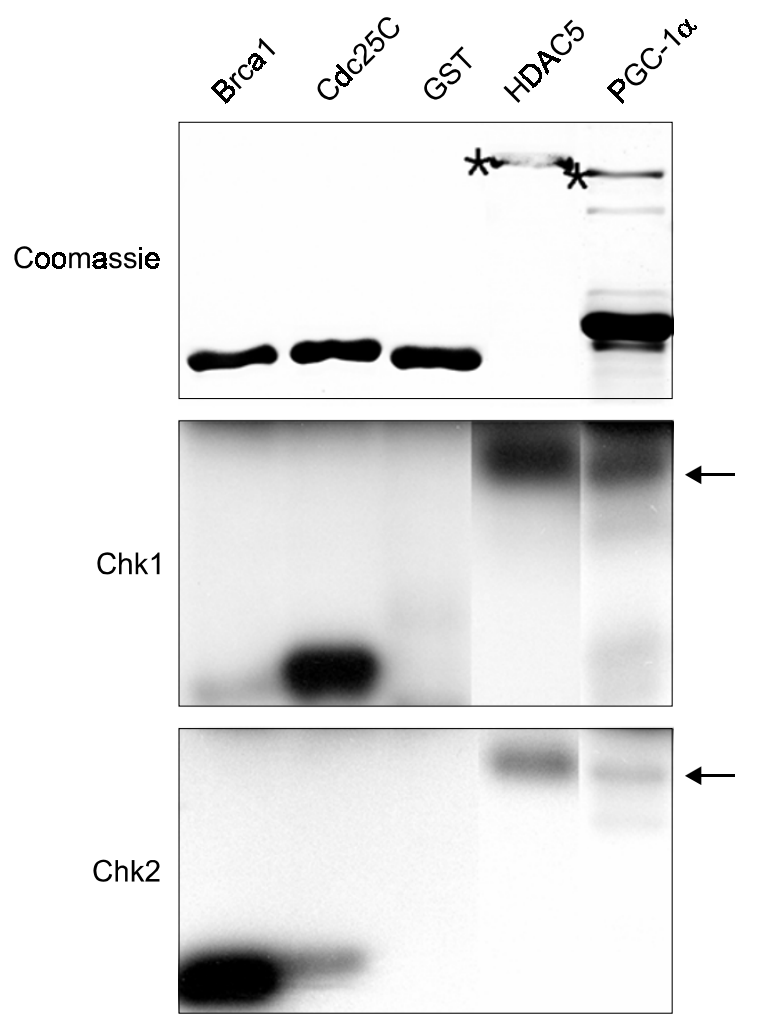

Figure 2. Phosphorylation of 200 amino acids fragments of HDAC5 and PGC- $1 \alpha$ by Chk1 and Chk2. The phosphorylation of GST-fusion proteins containing HDAC5 amino acids $378-600$ and PGC- $1 \alpha$ amino acids 201-400 was examined by in vitro Chk1 and Chk2 kinase assays. After SDS-PAGE separation of the reaction mixture, the gel was stained with coomassie blue to visualize the GST proteins and the phosphorylation signal was obtained by autoradiography. may be capable of forming a more favorable structure for Chk1-dependent phosphorylation. Secondly, the GST-HDAC5 (398-600) fragment may contain additional phosphorylation site(s) for Chk1 in addition to the Ser498 motif. We repeated the experiment several times and observed the same pattern of phosphorylation (data not shown).

\section{Ser498 of HDAC5 is specifically phosphorylated by Chk2}

To verify whether HDAC5 Ser498 is the target site for phosphorylation by Chk1 and Chk2, we substituted Ala for Ser498 in the GST-HDAC5 (398-600) fragment by site-directed mutagenesis and examined phosphorylation by Chk1 and Chk2 in vitro. While phosphorylation by Chk2 was completely abolished, the GST-HDAC5 Ser498Ala mutant was still phosphorylated by Chk1 at a similar level to wild type (Figure $3 \mathrm{~A}$ ). This result suggests that Chk1 may be phosphorylating a different site although we were unable to find a possible target sequence that matched the consensus phosphorylation motif within the 398-600 amino acids region. In addition, this result provided an explanation for why GST-HDAC5 containing the 13 amino acids motif was not phosphorylated by Chk1, as shown in Figure 1.

To further examine HDAC5 phosphorylation, we transiently expressed Flag-tagged full length HDAC5 wild type and the Ser498Ala mutant in HEK293 cells. HDAC5 wild type and the Ser498Ala mutant were immunoprecipitated using anti-Flag antibody and
A

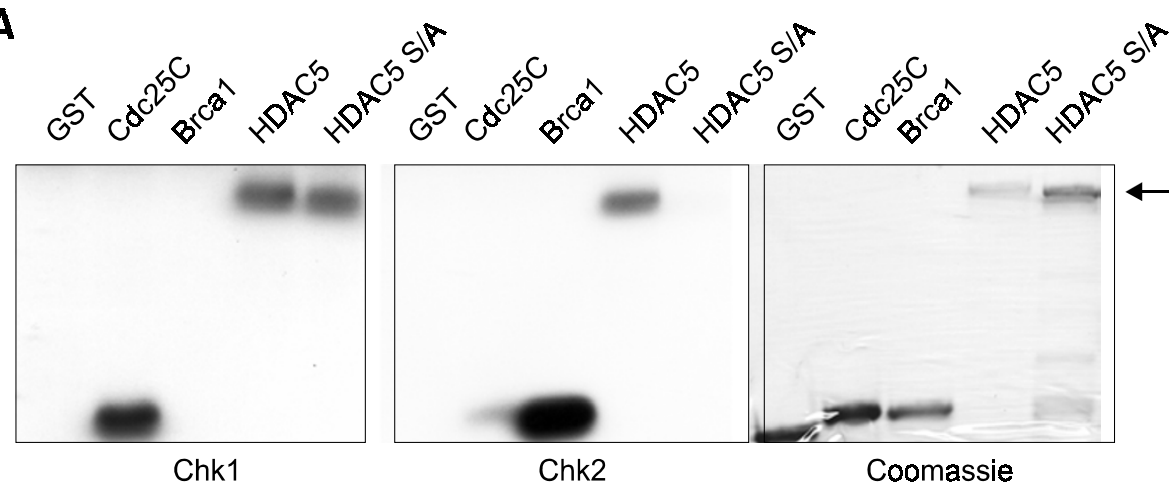

B

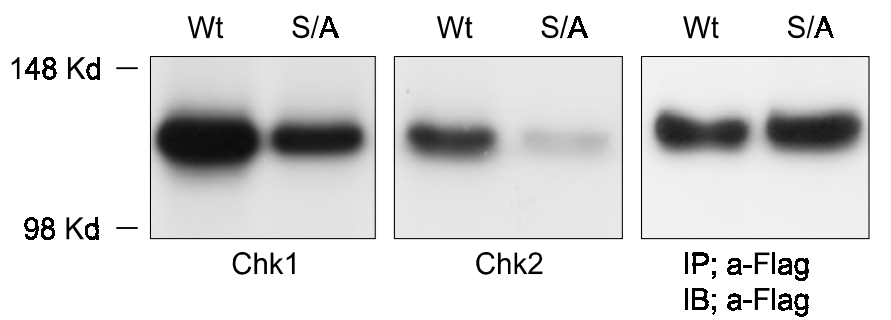

Figure 3. The Ser498 motif of HDAC5 is a specific target for Chk2. (A) Wild type and S498A GST-HDAC5 (386586) fragments were purified and used as substrates in Chk1 and Chk2 in vitro kinase assay. (B) Flag-tagged full length HDAC5 wild type and HDAC5 S498A were immunoprecipitated with anti-Flag (M2) antibody from transiently expressed HEK293 lysates and were used as substrates in Chk1 and Chk2 in vitro kinase assays. The levels of immunoprecipitated proteins were determined by Western blotting with anti-Flag (M2) antibody. 
were used as substrates for the Chk1 and Chk2 kinase assay. Consistent with previous GST-fusion protein results, full length HDAC5 was also strongly phosphorylated by both Chk1 and Chk2 (Figure 3B). In addition, the mutation of Ser498 abolished Chk2dependent phosphorylation while Chk1 still phosphorylated the Ser498Ala mutant. From these results, we concluded that the Ser498 motif of HDAC5 is a specific target site for Chk2 and that HDAC5 harbors additional target site(s) for Chk1.

\section{PGC-1 $\alpha$ is a specific substrate for Chk1 and Chk2}

To examine whether the PGC- $1 \alpha$ target motif is responsible for Chk1 and Chk2-dependent phosphorylation, we also substituted Ala for Ser285 of the GST-PGC-1 $\alpha$ (201-400) fragment by site-directed mutagenesis. In vitro kinase assay results using wild type and Ser285Ala GST-PGC-1 $\alpha$ fragments revealed that mutation of Ser285 completely abolished phosphorylation by both Chk1 and Chk2 (Figure 4A). In the IP-kinase assay using Flag-tagged full length PGC-1 $\alpha$, Chk1 and Chk2 both strongly phosphorylated PGC- $1 \alpha$ and consistent with Figure $4 \mathrm{~A}$, this phosphorylation was completely abolished by the Ser285Ala mutation (Figure 4B). These results suggest that PGC-1 $\alpha$ Ser285 is a specific and unique target site for both Chk1 and Chk2 phosphorylation.

\section{Discussion}

In this study, a number of novel substrates for Chk1 and Chk2 were identified by using a combination of a genome wide peptide library search and an in vitro kinase assay. The newly identified targets consist of several relevant proteins in the DNA damage response including transcription factors, DNA repair molecules and cell cycle regulatory proteins. Some of the target proteins have been shown to be directly involved in DNA damage repair. For example, Rad51D is required for recombinational repair of damaged DNA (Takata et al., 2001). FANCG/XRCC9 is one of the Fanconi anemia genes and is involved in DNA double strand break (DSB) repair in S phase (Yamamoto et al., 2003).

Cell cycle progression and cell growth are major targets of the DNA damage checkpoint. The list of newly identified targets contains cell cycle regulatory proteins. MAD1a is a component of the mitotic checkpoint (Iwanaga and Jeang, 2002). PP2A PR130 is the regulatory subunit of protein phosphatase 2 (PP2A), one of four major Ser/Thr phosphatases and is implicated in the negative control of cell growth (Hendrix et al., 1993). Cyclin $G$ is identified as a p53 target gene and recent studies suggest that cyclin $G$ negatively regulates the p53-mdm2 network in an ATM-dependent manner upon DNA damage (Ohtsuka et al., 2004). ST5 and GATA-3 have been implicated in cancer development. ST5 (suppression of tumorigenicity 5) was identified by its ability to suppress the tumorigenicity of Hela cells in nude mice and acts as an inhibitor of the RAS-ERK2 pathway (Majidi et al., 2000). GATA3 is known as a key regulator of $\mathrm{T}$-cell lineage determination. Interes-
A
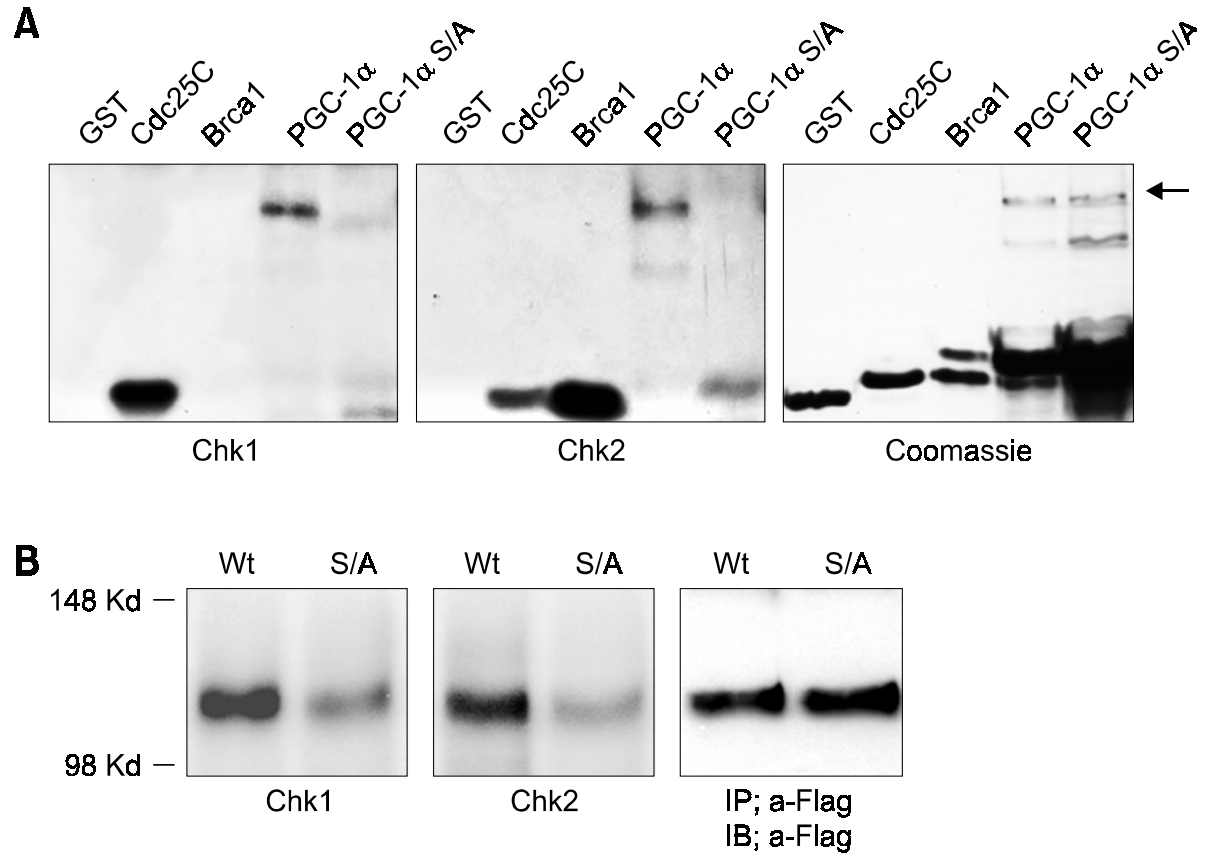

Figure 4. The Ser285 motif of PGC$1 \alpha$ is a specific target for both Chk1 and Chk2. (A) Wild type and S285A GST-PGC-1 $\alpha$ (201-400) fragments were purified and were used as substrates in Chk1 and Chk2 in vitro kinase assay. (B) Flag-tagged full length PGC-1 $\alpha$ wild type and PGC-1 $\alpha$ S285A were immunoprecipitated with antiFlag (M2) antibody from transiently transfected HEK293 cell lysate and were used as substrate in Chk1 and Chk2 in vitro kinase assays. The levels of immunoprecipitated proteins were determined by Western blotting with anti-Flag (M2) antibody. 
tingly, it has been reported recently that the expression level of GATA3 is closely related to breast cancer prognosis (Mehra et al., 2005). Whether these putative target proteins are bona fide in vivo target for Chk1 and Chk2 needs to be confirmed in future studies.

Previous studies reported that HDAC5 is involved in transcription regulation, cell cycle progression, differentiation and apoptosis (Yang and Gregoire, 2005). Although HDACs have been implicated in tumorigenesis (Wade, 2001), the role of HDAC5 in the DNA damage response is not clear. PGC-1 $\alpha$ is a transcriptional coactivator and plays an essential role in mitochondria biogenesis, fatty acid oxidation and gluconeogenesis (Puigserver and Spiegelman, 2003). However, whether PGC-1 $\alpha$ participates in the DNA damage response is largely unknown. In this study, we showed that HDAC5 and PGC- $1 \alpha$ are specific targets for Chk1 and/or Chk2 at least in vitro. While the exact roles of HDAC5 and PGC- $1 \alpha$ in DNA damage response need to be determined, further studies should provide important insight for understanding the function of Chk1 and Chk2 in a wide range of cellular responses upon DNA damage.

Previous studies suggest that Chk1 and Chk2 are functionally overlapping in response to genotoxic stress (Bartek and Lukas, 2001). The fact that Chk1 and Chk2 play redundant roles in DNA damage response is supported by the overlapping spectrum of their known substrates, most of which are shared by both kinases (Bartek and Lukas, 2003). However, despite their overlapping role in checkpoint signaling, the differences in biochemical property and biological requirements for Chk1 and Chk2 are remarkable. While protein level of Chk2 is constant throughout the cell cycle, Chk1 protein is mainly expressed in S and G2 phase (Lukas et al., 2001). The phenotype of Chk1 and Chk2 knockout and knockdown models indicate that Chk1 but not Chk2 is essential for development and viability (Hirao et al., 2000; Liu et al., 2000; Takai et al., 2000, 2002). Furthermore, cancer-related somatic abnormalities of Chk1 are relatively rare and only found in colon, stomach, and endometrim carcinomas so far (Bertoni et al., 1999; Menoyo et al., 2001), but somatic mutations of Chk2 have been found in diverse type of human cancers [reviewed in (Bartek and Lukas, 2001)]. These studies strongly suggest that Chk1 and Chk2 play distinct biological function through unique subset of target protein. Consistent with this notion, while a group of newly identified substrates in this study were phosphorylated by both Chk1 and Chk2, a sub-group of substrates were specifically phosphorylated by either Chk1 or Chk2. Thus, further studies will be important for mechanistic understanding of Chk1- and Chk2-specific biological functions.

\section{Acknowledgment}

We thank Eric Verdin for providing Flag-HDAC5 plasmid and Bruce Spiegelman for providing PGC- $1 \alpha$ cDNA. This work was supported by Korea Research Foundation Grant funded by Korea Government (MOEHRD, Basic Research Promotion Fund) (KRF-2005-003-E00015) and the Korea Science and Engineering Foundation through the Medical Science and Engineering Research Center for Cancer Molecular Therapy at Dong-A University.

\section{References}

Ahn BH, Min G, Bae YS, Bae YS, Min DS. Phospholipase D is activated and phosphorylated by casein kinase-II in human U87 astroglioma cells. Exp Mol Med 2006;38:55-62

Ahn J, Prives C. Checkpoint kinase 2 (Chk2) monomers or dimers phosphorylate Cdc25C after DNA damage regardless of threonine 68 phosphorylation. J Biol Chem 2002;277: 48418-26

Bartek J, Lukas J. Mammalian G1- and S-phase checkpoints in response to DNA damage. Curr Opin Cell Biol 2001;13: 738-47

Bartek J, Lukas J. Chk1 and Chk2 kinases in checkpoint control and cancer. Cancer Cell 2003;3:421-9

Bell DW, Varley JM, Szydlo TE, Kang DH, Wahrer DC, Shannon KE, Lubratovich M, Verselis SJ, Isselbacher KJ, Fraumeni JF, Birch JM, Li FP, Garber JE, Haber DA. Heterozygous germ line hCHK2 mutations in Li-Fraumeni syndrome. Science 1999;286:2528-31

Bertoni F, Codegoni AM, Furlan D, Tibiletti MG, Capella C, Broggini M. CHK1 frameshift mutations in genetically unstable colorectal and endometrial cancers. Genes Chromosomes Cancer 1999;26:176-80

Brown AL, Lee CH, Schwarz JK, Mitiku N, Piwnica-Worms H, Chung JH. A human Cds1-related kinase that functions downstream of ATM protein in the cellular response to DNA damage. Proc Natl Acad Sci USA 1999;96:3745-50

Chae HD, Yun J, Shin DY. Transcription repression of a CCAAT-binding transcription factor CBF/HSP70 by p53. Exp Mol Med 2005;37:488-91

Gonzalez S, Prives C, Cordon-Cardo C. p73alpha regulation by Chk1 in response to DNA damage. Mol Cell Biol 2003;23: 8161-71

Hendrix P, Mayer-Jackel RE, Cron P, Goris J, Hofsteenge J, Merlevede W, Hemmings BA. Structure and expression of a $72-\mathrm{kDa}$ regulatory subunit of protein phosphatase $2 \mathrm{~A}$. Evidence for different size forms produced by alternative splicing. J Biol Chem 1993;268:15267-76

Hirao A, Kong YY, Matsuoka S, Wakeham A, Ruland J, Yoshida $H$, Liu D, Elledge SJ, Mak TW. DNA damage-induced activation of $p 53$ by the checkpoint kinase Chk2. Science 2000;287:1824-7

Iwanaga Y, Jeang KT. Expression of mitotic spindle checkpoint protein hsMAD1 correlates with cellular proliferation and is 
activated by a gain-of-function p53 mutant. Cancer Res 2002; 62:2618-24

Lee JS, Collins KM, Brown AL, Lee CH, Chung JH. hCds1mediated phosphorylation of BRCA1 regulates the DNA damage response. Nature 2000;404:201-4

Liu Q, Guntuku S, Cui XS, Matsuoka S, Cortez D, Tamai K, Luo G, Carattini-Rivera S, Demayo F, Bradley A, Donehower LA, Elledge SJ. Chk1 is an essential kinase that is regulated by Atr and required for the $\mathrm{G}(2) / \mathrm{M}$ DNA damage checkpoint. Genes Dev 2000;14:1448-59

Lukas C, Bartkova J, Latella L, Falck J, Mailand N, Schroeder T, Sehested M, Lukas J, Bartek J. DNA damage-activated kinase Chk2 is independent of proliferation or differentiation yet correlates with tissue biology. Cancer Res 2001;61:4990-3

Majidi M, Gutkind JS, Lichy JH. Deletion of the $\mathrm{COOH}$ terminus converts the ST5 p70 protein from an inhibitor of RAS signaling to an activator with transforming activity in NIH-3T3 cells. J Biol Chem 2000;275:6560-5

Mehra R, Varambally S, Ding L, Shen R, Sabel MS, Ghosh D, Chinnaiyan AM, Kleer CG. Identification of GATA3 as a breast cancer prognostic marker by global gene expression metaanalysis. Cancer Res 2005;65:11259-64

Menoyo A, Alazzouzi H, Espin E, Armengol M, Yamamoto H, Schwartz S Jr. Somatic mutations in the DNA damageresponse genes ATR and CHK1 in sporadic stomach tumors with microsatellite instability. Cancer Res 2001;61:7727-30

O'Neill T, Giarratani L, Chen P, lyer L, Lee CH, Bobiak M, Kanai F, Zhou BB, Chung JH, Rathbun GA. Determination of substrate motifs for human Chk1 and hCds1/Chk2 by the oriented peptide library approach. J Biol Chem 2002;277: 16102-15

Ohtsuka T, Jensen MR, Kim HG, Kim KT, Lee SW. The negative role of cyclin $\mathrm{G}$ in ATM-dependent p53 activation. Oncogene 2004;23:5405-8

Puigserver $\mathrm{P}$, Spiegelman BM. Peroxisome proliferator-activated receptor-gamma coactivator 1 alpha (PGC-1 alpha): transcriptional coactivator and metabolic regulator. Endocr Rev 2003;24:78-90

Shieh SY, Ahn J, Tamai K, Taya Y, Prives C. The human homologs of checkpoint kinases Chk1 and Cds1 (Chk2) phos- phosphorylate p53 at multiple DNA damage-inducible sites. Genes Dev 2000;14:289-300

Stevens C, Smith L, La Thangue NB. Chk2 activates E2F-1 in response to DNA damage. Nat Cell Biol 2003;5:401-9

Takai $\mathrm{H}$, Tominage $\mathrm{K}$, Motoyama N, Minamishima YA, Nagahama H, Tsukiyama T, Ikeda K, Nagahama K, Nakanishi M, Nagahama K. Aberrant cell cycle checkpoint function and early embryonic death in Chk1(-/-) mice. Genes Dev 2000;14: 1439-47

Takai H, Naka K, Okada Y, Watanabe M, Harada N, Saito S, Anderson CW, Appella E, Nakanishi M, Suzuki H, Nagashima $\mathrm{K}$, Sawa H, Ikeda K, Motoyama N. Chk2-deficient mice exhibit radioresistance and defective p53-mediated transcription. Embo J 2002;21:5195-205

Takata M, Sasaki MS, Tachiiri S, Fukushima T, Sonoda E, Schild D, Thompson LH, Takeda S. Chromosome instability and defective recombinational repair in knockout mutants of the five Rad51 paralogs. Mol Cell Biol 2001;21:2858-66

Wade PA. Transcriptional control at regulatory checkpoints by histone deacetylases: molecular connections between cancer and chromatin. Hum Mol Genet 2001;10:693-8

Yaffe MB, Leparc GG, Lai J, Obata T, Volinia S, Cantley LC. A motif-based profile scanning approach for genome-wide prediction of signaling pathways. Nat Biotechnol 2001;19: 348-53

Yamamoto K, Ishiai M, Matsushita N, Arakawa H, Lamerdin JE, Buerstedde JM, Tanimoto M, Harada M, Thompson LH, Takata M. Fanconi anemia FANCG protein in mitigating radiation- and enzyme-induced DNA double-strand breaks by homologous recombination in vertebrate cells. Mol Cell Biol 2003;23: 5421-30

Yang S, KuoC, Bisi JE, Kim MK. PML-dependent apoptosis after DNA damage is regulated by the checkpoint kinase hCds1/Chk2. Nat Cell Biol 2002:4:865-70

Yang XJ, Gregoire S. Class II histone deacetylases: from sequence to function, regulation, and clinical implication. Mol Cell Biol 2005;25:2873-84

Zhou BB, Elledge SJ. The DNA damage response: putting checkpoints in perspective. Nature 2000;408:433-9 